The following is the final version prior to publication of Gurnell, A.M, Rinaldi, M., Buijse, A.D., Brierley, G., Piégay, H. 2015. Hydromorphological frameworks: Emerging trajectories. Aquatic Sciences, 78(1), 135-138.

The final publication is available at Springer via http://dx.doi.org/10.1007/s00027-015-0436-1.

\title{
HYDROMORPHOLOGICAL FRAMEWORKS: EMERGING TRAJECTORIES
}

A.M. Gurnell1 ${ }^{1}$ M. Rinaldi², A.D. Buijse ${ }^{3}$, G. Brierley ${ }^{4}$, H. Piégay ${ }^{5}$

1 School of Geography, Queen Mary University of London, London, United Kingdom

2 Department of Earth Sciences, University of Florence, Italy

3 Deltares, Boussinesqweg 1, 2629 HV Delft, the Netherlands

4 School of Environment, University of Auckland, Auckland, New Zealand

5 University of Lyon, CNRS UMR 5600 Environnement Ville Société, Site ENS, Lyon, France

\section{ABSTRACT}

This paper forms a post-script to a Special Issue of Aquatic Sciences devoted to the rationale, nature and application of a multi-scale, hierarchical framework for developing process-based understanding of catchment to reach hydrology and fluvial geomorphology (termed hydromorphology). It considers some potential future directions for hydromorphological frameworks in relation to their use as 'tool kits' for hydromorphological river assessment and management; the ways in which such development needs to be integrated with other river sciences and data sets to support integrated management of river ecosystems; and the stakeholder context in which development needs to take place to ensure maximum benefits for both humans and river ecosystems.

KEY WORDS: Hydromorphology, river assessment, river management

\section{INTRODUCTION}

As editors of this Special Issue (Angela Gurnell, Massimo Rinaldi), and Research Director (Tom Buijse) and Advisory Board members (Gary Brierley, Hervé Piégay) to the REFORM (Restoring rivers FOR effective catchment Management) project, we conclude this Special Issue of Aquatic Sciences by considering how hydromorphological frameworks such as the REFORM framework may contribute to multi-purpose, knowledge-based river management in the future.

This Special Issue has proposed, explained and applied the REFORM hydromorphological framework for developing understanding of river behaviour to support management of European rivers. The framework integrates information on the hydrology and fluvial geomorphology (termed 
hydromorphology) and vegetation of rivers, floodplains and catchments and the human pressures and direct interventions that affect these systems. The framework is multi-scale, incorporating spatial scales from biogeographical region to geomorphic and hydraulic units within river channels and floodplains, and incorporating temporal scales that allow these spatial units and the cascade of processes that link them to be tracked from the past to the present. Through the evaluation of past and present indicators of processes and forms, the framework tracks trajectories of changes in the spatial units, particularly within river and floodplain reaches, as a basis for considering potential river responses to likely future climate and management scenarios. While such an approach is not completely new to certain scientific communities, particularly within geomorphology, here it has been devised within the context of a large multi-disciplinary group composed of hydraulic engineers, hydrologists, geomorphologists and riparian and aquatic ecologists involved in river science and management within many different biogeographical settings across Europe. It has also been tested and refined through its application to contrasting European rivers and their catchments. These aspects have allowed the framework to acquire considerable robustness in terms of its applicability. Overall, the framework guides effective data analysis and synthesis within a process-based approach. It permits the development of understanding and the formal assessment of the character, morphodynamic behaviour and condition of river reaches. Therefore, this open-ended, flexible framework provides an integrated suite of tools to support river management within Europe and potentially in other areas of the World.

The following thoughts provide a brief post-script to this Special Issue, since we consider some potential future directions for hydromorphological frameworks in relation to three themes (i) the scientific development of the REFORM and other frameworks as 'tool kits' for hydromorphological river assessment and management; (ii) the ways in which such development needs to be integrated with other river sciences and data sets to support multi-purpose, sustainable and integrated management of river ecosystems; (iii) the stakeholder context in which development needs to take place to ensure maximum benefits for both humans and river ecosystems.

\section{SCIENTIFIC DEVELOPMENT OF HYDROMORPHOLOGICAL FRAMEWORKS}

Three different themes are likely to be particularly influential in the future development of hydromorphological frameworks. The first is the way in which the theoretical, conceptual and methodological underpinnings of frameworks may evolve; the second is the way in which scientific information may be extracted and incorporated from new data sources; and the third is the way in which these first two themes may be coupled to address emerging process-form relationships across cascades of time and space scales.

The framework proposed in this special issue is deliberately open-ended, allowing users to develop scientific understanding of the functioning of their catchment and its rivers by deviating from a prescribed 'cookbook' and emphasising the fact that rivers are highly variable, complex systems. 
Although similarities between rivers may be observed, none are identical. Therefore, one important aspect of the future development of this and other open-ended frameworks is that they need to be used flexibly and intelligently; continually testing, adapting and updating them to make the most effective use of local data sets and knowledge to interpret hydromorphological forms, processes and trajectories. Such an evolutionary approach to the development of a framework ensures its sustained robustness, applicability and relevance within different settings. Furthermore, documenting and sharing methods that are found to improve the outcomes of framework application are essential to ensuring the success of such an adaptive development trajectory and the generation of increasingly informative outcomes.

Another important aspect of the future scientific development of frameworks is the assimilation of data from new data sources. Environmental data acquisition and processing are advancing extremely rapidly. New sensors and platforms (e.g. drones, new very high resolution satellites sensors) are supporting the acquisition of high-resolution time series of hydromorphological variables and highresolution spatial distributions of hydromorphological phenomena (forms, materials, textures, structures). Increasingly these data sets provide the information needed to implement a hydromorphological framework, with field observations by humans needed for calibration and quality control but no longer the sole means of primary data acquisition. Furthermore, GIS algorithms and modelling tools that process these data sets are advancing rapidly, opening numerous possibilities for the automation of delineation and characterisation of spatial units; the production of indicators of processes, forms, and human interventions; and the establishment of procedures for identifying scenarios of changes, or targeting reaches for planning and design actions (e.g. mapping hydromorphological alteration or river body status). This explosion in the types and quantities of available data indicates many future possibilities for improving the ability of frameworks to generate highly informative outputs concerning river landscapes and their functioning, and for achieving these in a much shorter time and at a smaller financial cost than at present. We also anticipate that this advance in remotely sensed river characterisation will permit new ways of monitoring river processes, identifying the effects of human alterations, recording river rehabilitation interventions and assessing their success.

Ultimately, hydromorphological frameworks aim to advance understanding of process-form relationships and their responses to human interventions across multiple time and space scales. By allowing frameworks to evolve in response to new knowledge and within different environmental settings, and to assimilate information from new data sets of increasing spatial and temporal resolution, new emergent properties of river systems and their environments will be revealed. The flexibility of procedures outlined within the REFORM framework allows for the generation of additional insights into the critical space and time scales at which these need to be investigated. While it is impossible to guess what these properties and scales may be, they will undoubtedly influence the structure and implementation of future hydromorphological frameworks in profound ways. It is certainly clear that European catchments and river systems are experiencing widespread, notable 
changes. For example, many rivers are being affected by significant afforestation and, as a consequence, reduced runoff and sediment delivery and increased wood delivery. This illustrates that we work on highly dynamic systems experiencing important changes that we must understand if we are to find innovative solutions for future river management.

\section{INTEGRATION WITH OTHER RIVER SCIENCES}

If we are to manage rivers in a truly integrated way, hydromorphological frameworks need to absorb or integrate with relevant tools from other areas of river science. While the framework reported in this Special Issue incorporates aquatic and riparian vegetation, it does not incorporate other biota or their habitat requirements, nor does it incorporate biogeochemical data and processes. Although such integration is technically feasible, to date biologists, hydrologists, geomorphologists and biogeochemists have not always shared the same desired outcomes, space scales or time scales, with the result that they often view problems from very different perspectives that are difficult to merge. Perhaps the most challenging issue requiring significant attention is the development of routine monitoring systems for habitats (particularly for macroinvertebrates and fishes) and ecological processes such as material mobilisation, retention or transformation which go beyond current systems that emphasise water quality and flow conditions. Present approaches do not provide the appropriate spatial resolution to capture the impacts of channel-floodplain forms or vegetation and sedimentary structures. Without a convergence in the way routine biological and hydromorphological data sets are collected, it will continue to be very difficult to isolate the physical drivers that are critical to river ecosystem health.

Such an advance not only requires more detailed spatial sampling to link biogeochemical processes and biota and their life stages to morphological, sedimentological and hydraulic conditions, but it also requires sampling to extend beyond the river channel, into the riparian zone of the river corridor and into the sub-surface. Furthermore, such data sets need to be gathered over prolonged periods and are likely to be most useful when coupled with sampling of water and sediment quality, since biological responses to changes in physical properties are complex and likely to take a considerable length of time. In relation to the monitoring period required to capture a biological response, it is crucial to distinguish the hydromorphological sensitivity of the river environment that is being investigated. While some river systems change very slowly through time, allowing physical interventions to persist and changes in processes to be absorbed, other systems are extremely sensitive, showing rapid adjustments to changes in processes and physical modifications (especially those systems that are subjected to threshold-induced changes in state and process-form regime). Thus the sensitivity of the river system affects the monitoring period that is required to assess hydromorphological adjustments let alone biotic ones. As a result, monitoring needs to take account of the decadal timescales that are usually considered by geomorphologists as well as the shorter periods that are more typical of biological monitoring schemes. One way of making progress towards such an aim is to devise temporally and spatially nested schemes relevant to the hydromorphological sensitivity of the investigated system. 
Such data sets are essential to not only assessing ecosystem health but also to providing a sound scientific basis for devising appropriate rehabilitation measures. However, before such advances can be implemented, research is needed to establish the required characteristics of sampling designs. These designs need to be appropriate to the sensitivity of the river system, to be applicable at reasonable cost, and to generate information on system functioning and the effectiveness of management interventions that is readily incorporated into frameworks or complementary tools (i.e. measuring the right things in the right place at the right time).

\section{STAKEHOLDER INVOLVEMENT AND THE APPLICATION OF FRAMEWORKS}

The REFORM framework was developed in collaboration with river managers. Such collaboration with all stakeholders is crucial to the future development of such tools and their successful application.

Collaboration promotes the use of a common 'language' and a common understanding of both human and river ecosystem issues. As a result, it promotes co-production of knowledge and is more likely to result in mutually acceptable approaches to management. In an even more practical sense, such collaboration is essential to ensuring that science-based tools meet regulatory requirements.

Within Europe, assessment of hydromorphological status is required as a part of ecological status assessment by the Water Framework Directive. Status assessment is used for classifying and monitoring water bodies. To date, hydromorphological assessment methods have often focused upon the occurrence and spatial configuration of physical habitats, placing little emphasis on system dynamics including "pressure" or "response" variables. The application of a hydromorphological framework approach such as that proposed in this Special Issue overcomes this problem. Furthermore, through the adoption of an open-ended collaborative approach to framework development and application, a common understanding can be built into hydromorphological assessments and consequential actions that are concordant with local environmental conditions. In addition, river restoration and policy that are only focused on reaching 'good status' cannot be pursued in isolation because they may not be accepted by society. Collaborative application of a hydromorphological framework allows a common understanding to be developed among stakeholders in relation to both environmental and societal needs. As a consequence, integrated river management can evolve at a catchment or district scale as stakeholders converge on flexible solutions for both society and the river ecosystem.

Across the World, humans have used river systems for multiple purposes, receiving multiple benefits with varying impacts and responses in space and time. Therefore, river management has to address many issues in addition to sustaining river ecosystems, including management of water resources, flood risk, and a range of other economic, social and cultural aspects. The full engagement of stakeholders in these issues, emphasising communication (speaking and listening), collaboration, and the production of knowledge through the application of tools such as the framework presented in this special issue, provides the most sustainable and effective way of progressing such management. The resulting management pathway should then embrace innovative rehabilitation, enhancement or 
mitigation actions at multiple scales, suited to local conditions, and in the context of the ecosystem services and human benefits that are also supported. Inevitably, these are place-specific situations and applications, for which generic hydromorphological frameworks such as the procedures outlined in this special issue provide a coherent suite of foundations and guiding principles.

\section{CONCLUSIONS}

Returning to the title of this paper, we conclude with some key messages related to the future trajectories of hydromorphological frameworks for river assessment and rehabilitation.

i. Frameworks allow us to consider rivers and their catchments in an integrated way, and so to understand the causes and consequences of changes across space and time and to develop sustainable river basin management strategies. The flexible evolution and application of frameworks will drive us towards increasing knowledge of the spatial and temporal aspects of catchment and river dynamics and the emergence of innovative management strategies.

ii. At the reach scale, the application of a framework approach will allow us to develop understanding of how sensitive river reaches are to changes at multiple space and time scales; to identify appropriate, process-based approaches to their rehabilitation; and to recognise river reaches that are functioning well and should be conserved. Inevitably, such applications should be viewed in their catchment context.

iii. Frameworks allow us to integrate information from many data sources and need to increasingly embrace new data acquisition technologies and improved sampling schemes that can provide new perspectives

iv. Finally, and most importantly, the application of hydromorphological frameworks needs to incorporate multi-disciplinary science perspectives and engage stakeholders. This is essential because no single discipline has the solution to river rehabilitation and management problems and solutions need to be accepted by society. A multi-disciplinary approach allows us to develop integrated scientific understanding of system functioning; and to balance the needs of the river and society within the actions that are devised, including those of river maintenance or regulation (e.g. vegetation maintenance; channel clearing practices), as well as process-form rehabilitation and conservation. Ongoing collaborations with practitioners and end users are required to deeply embed these developments if they are to meet their full potential.

\section{ACKNOWLEDGMENTS}

This paper forms a postscript to a Special Issue that reports on research funded through the European Union's FP7 programme under Grant Agreement No. 282656 (REFORM). 